\title{
Da Administração das Sociedades Anonymas
}

\author{
OBSERVAÇÃO PRELIMINAR
}

Quando Pateri Giovanni compoz sua excellente obra sobre sociedades anonymas, foi animado, disse elle, no prefacio, pelo desejo de dar aos accionistas uma noção dos direitos que têm. Refere o emerito mestre commercialista que incriveis abusões reinam na Italia em relação a direitos de accionistas. Pelo que diz $\mathrm{Pa}$ tèri, vê-se que la muita gente pensa que as acções dão lucro, dividendo e até juro sem o menor esforço da parte do accionista, do mesmo modo por que as arvo. res silvestres produzem o fructo, e as abelhas o mel.

Queixa-se Pateri de que os accionistas não se interessam pelo andamento das sociedades, e deixam todá a vida social abandonada ao arbitrio da administração, a qual, justàmente por falta de fiscalização, abusa, na maioria dos casos. Aqui, no Brasil, tem cabimento o que diz Pateri Giovanni, cumprindo accrescentar que os accionistas (em consequencia da facilidade com que a metade dos brasileiros póde injuriar, pelas columnas pagas dos jornaes, a outra metade), antes de entrarem as sociedades em liquidação, mesmo quando éstas são bem administradas por gente honrada, movem, pela imprensa, contra os directores, uma campanha de diffamação, contra a qual não dão recurso nossos tribunaes. Pareceu-me que era tempo de, em fugidio escorço, mostrar o que pódem os accionistas contra os desmandos dos administradores. O 
Brasil é a terra das sociedades anonymas, e até policia já se quiz fazer por este processo!! ... Entretanto quão pequeno é o numero dos que conhecem os principios que regem tão uteis institutos!... Que pessoas sabem o que pódem os socios, para terem influencia decisiva no desenvolvimento das sociedades de que fazem parte?

Pelo que exponho no correr deste artigo, ver-se-á que nossa lei é imperfeita no tocante aos recursos dados aos accionistas, mas tambem é força reconhecer que, bem empregados os poucos recursos legaes, pódem dar resultados taes, que, na maioria dos casos, evitem a já classica campanha de diffamação com que se locupletam os jornalistas, campanha cujo unico resultado é augmentar os prejuizos dos infelizes accionistas...

Lembrou-me indicar aos moçors, nossos futuros legisladores, facilitassem o recurso ao poder judiciario, visto escrever eu particularmente para a mocidade, que vae amanhan ser responsavel pelos destinos de nossa patria. Occorreu-me, porém, logo uma difficuldade de grande vulto.

Como é sabido, o rapido despacho dos pleitos judiciaes constitue hoje, no Brasil, a rara excepção. Contra a demora, fala-se em remédio, mas o apontado (mudança de legislação) é evidentemente inefficaz, e tem o defeito de dar uma esperança que afasta nossa attenção do gravissimo problema social. Como é sabido pelas obras literarias de Shakespeare, Racine, Molière, Goethe e Castello Branco (fontes historicas importantissimas para os jurisperitos), antes da revolução de 1889, andavam os povos europeus nas mesmas condições em que a nossa patria está em pleno seculo 20. Foi evidentemente a reforma social, realizada durante o seculo 19 , que trouxe modificação a tal estado de coisas. Não creio, seja dicto incidentemente, que fosse ésta demora na administração da justiça o factor primordial da revolução. francesa, nem quero que se julgue que prophetizo cataclysmos sociaes. $O$ que affirmo apenas é que a melhora da distribuição da justiça na Europa caminhou de par com o progresso em geral, e foi producto das ideas novas, particularmente cultivadas pelos sociologos, aos quaes mais deve a sociedade moderna europea seu bem estar do que aos legisladores. 
Na pequena parte de critica que contém meu modesto artigo, ha unicamente o desejo de ser util á minha patria cujas condições economicas não são das mais lisonjeiras, e que seguramente terá proveito, si vir em pé de prosperidade, e não abandonadas e criticadas em artigos diffamatorios pelos proprios socios, as empresas particulares, que dentro della exploram várias iffdustrias." Do mesmo modo que Pateri Giovanni, eu peço para mim aquella tolerancia que reclamava $\mathrm{Pe}-$ trarca, quando procurava inflammar os grandes da Italia para a libertarem:

"Io parlo per ver dire

Non per odio d'altrui nè per disprezzo".

Alegrar-me-ei si os moços, ao meditarem sobre os varios problemas que deixo indicados, sentirem a necessidade de dar aos accionistas o braço forte e a acção prompta de uma justiça rapida, como requerem os negocios mercantis, e si os socios de sociedades anonymas reconhecerem que lhes suggeri meios de intervirem efficazmente, pelos processos legaes, no andamento das sociedades anonymas de que fazem parte. 


\section{Da Administração das Sociedades Anonymas}

1. Estão de accordo todos os commercialistas em que é da probidade e diligencia dos administradores que particularmente depende o bom exito das sociedades anonymas (Bing, De la Societé an. en Dr. it., p. 275). Não dizem porém quaes são os principaes motivos de abuso das directorias, nem quaes os remedios. Parece-me que as causas primordiaes são: a desidia dos fiscaes e a extensão absurda que se tem dado á ratificação dos actos dos administradores pela assemblea geral. Corre, como iivre de contestação, que a approvaçã̃o do balanço, das contas e do relatorio, tem qualquer semelhança com o baptismo, que lava todos os peccados. Si os fiscaes fossem zelosos, si á ratificação da assemblea se applicassem, com decisão e senso juridico, as regras relativas á materia que o Direito Civil sábia e laboriosamente organizou, outra seria a sorte das sociedades anonymas. Neste artigo, devo me occupar da administração, attendendo ao modo de constituir a directoria, aos seus direitos e deveres, reservando para um outro o que diz respeito á sua responsabilidade, assumpto de tomo.

Cumpre, ao estudar este ponto do Direito relativo ás sociedades anonymas, ter presente que, achando-se a administração da sociedade, por assim dizer, no centro della, relacionando-se com todas as suas operações, natural é que, no seu estudo, nos utilizemos de principios de todas as partes do Direito relativo a tal genero de associações.

2. Por dois modos, em regra, são nomeados os administradores: pela assemblea geral (D. 434 , art. 97 $\S 2$ ) e pelos socios fundadores, nos estatutos (D. 434, art. $62 \S 3$ ). Póde porém succeder que o Governo te- 
nha interesse em fazer a nomeação de um ou de mais de um membro da administração. E' o que succede com o Banco do Brasil, no qual dois administradores são de nomeação governamental (D. n. 1.455 de 30 de Dezembro de 1905, art. 10).

A substituição dos administradores é regida pelo contracto social, ou pelos estatutos (art. 100 do D. 434). O substituto, em caso de silencio dos estatutos, será nomeado pelos que se acharem em exercicio e pelos fiscaes (D. 434 art. 103). O substituto sómente servirá pelo tempo que restar para se completar o prazo do mandato do administrador substituido (D. 434, art. 104). Claro, porém, parece-me que diversa póde ser a tal respeito a disposição dos estatutos, mormente attendendo a que é licito ser a directoria reformada, não em bloco, mas parcialmente (Bing, p. 283). Permitte expressamente o art. $97 \S 3$ do D. 434 a reeleição dos directores. E' incontestavel comtudo que os estatutos pódem prohibir essa reeleição (Vavasseur, Tr. des Soc. n. 794).

3. O numero dos administradores foi fixado em dois ou mais pela nossa legislação (D. 434, art. 97). Muito divergem, a este proposito, as leis dos diversos povos (Bing, pgs. 274 e 275). Não vejo a menor vantagem neste onus imposto ás sociedades de manter uma numerosa directoria, e creio que, em dadas hypotheses, o director unico é preferivel (Bing, pag. 275).

Pódem ser socios, ou não (D. 434, art. 99). Diversa é a disposição do Direito frances (Vavasseur, Tr. des Soc., n. 792).

Seu mandato é, ora estipendiado, ora gratuito (D. 434, art. 98). E' revogavel, sem nicessidade de causa justificativa, e não póde durar mais de seis annos (D. 434 art. $97 \S 1$ ). Os honorarios são, ora fixados nos estatutos, ou no contracto social, ora deixados ao arbitrio da assemblea geral, consistem em quantia fixa, ou se formam por porcentagem etc. E'stas modalidades combinam-se de diversos modos na práctica. Comquanto pareça extraordinario prestar alguem serviços gratuitos, deixa de ser extranho o facto, considerando-se que o administrador póde ter na sociedade grandes interesses, que o levem a promptificar-se a por 
ella trabalhar sem umą remuneração directa. Tem entretanto seu trabalho uma remuneracão indirecta. Quanto ao modo de se calcular a bonificação dos administradores, disputa surgiu na vida mercantil. Não póde ella ser calculada sobre a renda bruta, como permitte o art. 98 do D. 434, que, conforme mostrou o C. ${ }^{\circ}$ Andrade Figueira, mal consolıdou o art. 42 dó D. 8821 de 1882. Quando o D. 8821 falou em declaração expressa em contrário, não se referia á possibilidade de mandarem, os estatutos fosse a porcentagem tirada do lucro bruto, mas do lucro liquido, sem abatimento do fundo de reserva. Foi infeliz a deslocação da cláusula salvo disposiçâo em contrário. E' este o modo de pensar de Ouro Preto, Gumersindo Ribas, Brasilio Machado, Clovis Bevilaqua e Duarte de Azevedo. Carvalho de Mendonça, que registou essas opiniões, é do mesmo sentir (Tratado, v. 4, p. 42). Tambem são do mesmo parecer Didimo (n. 246) e Vampré (n. 612).

Quanto ás pessoas que não pódem administrar sociedades anonymas, ha a referir que, no art. 3 , já o nosso Cod. Commercial estabelecêra algumas prohibicões. Hoje estão definidas na última parte do art. 233 do Cod. Penal. São ellas: governadores e commandantes de armas dos Estados, magistrados, officiaes de fazenda dentro dos districtos em que exercerem as suas funcções, officiaes militares de mar e terra, salvo si fôrem reformados e os dos corpos policiaes.

Não pódem ser directores de companhias que gozem de favores do Governo Federal definidos em lei os deputados e senadores, importando a aceitação do cargo perda do mandato (Const. Fed,, art. 24). Que dizer dos fallidos? Vampré, fundado nos arts. 2 e 3 do Cod. Com., entende que são elles incapazes de ser administradores de uma sociedade anonyma. C. de Mendonça entende que, neste ponto, não se acha mais em vigor o Cod. Com. (Dir., v. 92, p. 202, nota 240). O douto professor Steidel sustenta que a incapacidade do fallido é não só de Direito, por continuar em vigor o Cod. Commercial, art. 2, n. 4, mas tambem de facto, em outra que é impossivel comprehender-se que tenha elle bens, pois todos ficam sujeitos a ser arrecadados para pagamento dos credores emquanto elle não se rehabilitar. C. de Mendonça reconhece que é de difficil 
applicação sua doutrina, porque os credores irão arrecadando "os bens novamente adquiridos e até o proprio estabelecimento" (Das Fallencias, v. 1, n. 247). Na qualidade de director de sociedade anonyma porém, não precisa o fallido ter bens, e o que recebe é, em regra, só o necessario para a sua subsistencia (L. 2024, art. $45, \S 3)$. O Dr. Steidel, interpretando o art. $45 \S 3 \mathrm{da}$ L. n. 2024, sustenta que deve ser arrecadado, em proveito dos credores, tudo o que não for estrictamente indispensavel á manutenção propria e da familia do fallido, mas tambem sustenta que o fallido póde ser director de sociedade anonyma, porque exercer tal cargo não é commerciar ainda quando a sociedade é mercantil.

Com ésta intelligencia, é claro que só modicos honorarios recebidos pelo fallido pódem ser por elle aproveitados. Em todo caso, ha divergencia entre a opinião de Vampré, que é a de Bento Faria (Cod. Com. nota 12), e as dos Drs. C de Mendonça e Steidel. Prefiro a deste último commercialista patrio, que não reconhece capacidade no fallido para commerciar, mas para administrar sociedades anonymas.

Outras prohibições ha relativas particularmente aos empregados de certas secretarias ra Federação. Em nosso Estado tem sido inconvenientissimo para os interesses particulares não haver prohibição relativamente aos empregados administrativos. Outras profissões consideram-se, no Direito frances, incompativeis com o cargo de administrador de sociedade anonyma (Vavasseur, n. 793 e Pandectes Françaises, ns. 11263 e 11270).

Não é raro que uma sociedade anonyma seja incorporada por outra. Tem-se entretanto perguntado si uma sociedade anonyma póde dirigir outra. Não vejo grandes inconvenientes nisso. Demais não é raro que duas sociedades tenham directoria commum, ou que uma sociedade seja de facto (as mais das vezes em razão de dependencia pecuniaria) dirigida por outra.

Carvalho de Mendonça dá notícia da questão e a resolve pela negativa.

4. Este exame das pessoas capazes de exercerem os cargos da directoria de uma sociedade anonyma, leva-me a um estudo práctico das qualidades requeridas num director. Infelizmente, entre nós, parece que a 
opinião geral é de que basta ser bacharel em Direito. Gilbart, no seu utilissimo e notavel Tratado dos Bancos, estabelece as seguintes condições relativamente aos directores de bancos:

«1) Deverá gozar da confiança pública; 2) será versado em negocios commerciaes; 3) será homem da maior inteireza e de antes quebrar que torcer; 4) de influencia de crédito; 5) estará em boas circumstancias pecuniarias e 6) deverá ser homem em estado de prestar attenção aos negocios do estabelecimento». (Traducção de Castro, pags. 236 e segs.). O que Gilbart diz dos tancos póde ser dicto das sociedades anonymas. Com o espirito práctico dos ingleses, apresenta ainda Gilbart muitas outras regras vantajosissimas. Referindo-se á directoria em conjuncto, faz sentir quanta vantagem ha em reunir jovens a velhos, de rodo que a iniciativa ardente daquelles se harmenize com a experiencia e prudencia destes. Tira tal conselho do Estadista de de Taylor (Gilbart. v. 1, p. 240). A substituição parcial é outra medida excellente, que infelizmente vae de encontro aos nossos habitos, pois o brasileiro mostra grande tendencia para fazer do cargo seu unico meio de vida. Não ha entretanto necessidale de se entregar o director exclusivamente á administração da sociedade. Para isto ha os gerentes.

5. Por serem muitos os negocios das sociedades anonymas e exigirem certos conhecimentos technicos, que é natural não possuam os directores, pódem elles nomear agentes ou gerentes de sua confiança, ficando responsaveis pelos actos destes prepostos. (D. 434, art. 101 §2). O gerente é chamado directeur, no Direito Frances, e direttore no italiano.

Ao proposito de direcção, escreveu Taylor, no Estadista: "A qualidade mais importante para um homem que occupa uma alta posição na administração do Estado, é saber servir-se dos outros, pois o que elle faz por intervenção alheia deve sempre exceder grandemente ao que a actividade directa e individual de uma só pessoa póde conseguir por si mesma. (Gilbart, v. 1, p. 24) O direito de nomear agentes em nada differe do de nomear outros empregados. Si os estatutos nada dizem a tal respeito, cabe o direito de nomeação 
aos directores, ficando responsaveis pelos actos de seus prepostos no caso de má escolha, ou de falta de vigilancia. Si os estatutos porém deram á assemblea essa faculdade (Vidari, Le Società, n. 488), o que não é desejavel, mesmo porque ella viria tirar a pequena parcella de força que têm os directores sobre os empregados das sociedades anonymas, não poderão os directores substituir os prepostos e demais empregados sem audiencia da assemblea. Diz Vampré que, pelos actos dos agentes nomeados pela assemblea, nenhuma responsabilidade cabe aos administradores. Assim é de facto, sendo difficil de se comprehender a vigilancia do director sobre um agente autonomo pela nomeação da assemblea. A regra porém é a da responsabilidade do chefe, no caso de falta de vigilancia, ou ao menos no de desidia notavel.

Figuremos os casos de loucura do gerente, de fuga e abandono do logar, de deixar o serviço entregue a pessoa manifestamente incompetente: não deverá o director, em taes casos, convocar immediatamente a assemblea, e, no caso de o não fazer, ficar responsavel pelas consequencias de sua omissão? Da matéria occupar-me-ei quando me referir á responsabilidade da directoria.

Si é de grande vantagem que os administradores encontrem auxílio em agentes ou prepostos, damnosissimo será para a sorte da sociedade que abandonem a direcção dos negocios inteiramente a estes agentes, como infelizmente succede com frequencia entre nós. Não quer isto dizer que não dêem certa autonomia aos gerentes e demais empregados: si exigir que os agentes, os consultem a todo momento, nunca estes aprenderão a pensar por si, diz Gilbart (V I, p. 26).

6. Com os agentes, ou melhor, gerentes das sociedades anonymas (Lyon Caen, 298, Manuel), não devem ser confundidos os individuos que agenciam negocios para a companhia, as mais das vezes ambulantes, e quasi nunca trabalhando dentro do predio onde tem a sociedade sua séde. Com frequencia, estes ultimos prestam seus serviços a várias sociedades, ou a varios negociantes. Como são suas attribuições muito limitadas, é a responsabilidade da sociedade pelos actos delles quasi nulla. O trabalho delles é procurar 
freguezes ou clientes, propondo-lhes os negocios dos commerciantes que representam, mas ficando, em regra, o commerciante livre de acceitar, ou não, a transacção ou o freguez. Estes agentes, verdadeiros cas $a$ dores de freguezes, são homens mal vistos (Vivante v. I, n. 81, Thaller n. 25 e Lyon Caen, Manuel, n. 29).

Cumpre pois que se lembrem disto as pessoas que com taes agentes tractarem. Eu os collocaria entre os corretores (Cod. Com. art. 45), tendo presente o que dispõem os arts. 27 e. 28 do D. n. 1359 e mais disposições que regem o exercicio da profissão de corretor.

$\mathrm{O}$ que desejo que fique ben accentuado neste artigo, é que não devem ser considerados como representantes ou prepostos da sociedade anonyma, nem como pessoas por cujos actos responda ella, individuos, sedentarios ou ambulantes, que para ella andem em busca de negocios.

7. Disse eu que a directoria da sociedade anonyma é eleita pela assemblea, ou nomeada no acto de sua constituição: estatutos ou escriptura pública. Qual porém a maioria exigida para ésta nomeação? Deverão os votos ser por capital, ou por socio? Si ha caso em que, nas sociedades anonymas, devesse prevalecer 0 capital, é justramente o da escolha da administração. Pelo nosso systema porém a regra é que as assembleas resolvem per capita, como se vê na legislação consolidada no art. 132 do D. 434. Pódem comtudo os estatutos modificar este rigor muito democratico, mas pouco mercantil, porque o art. 141 do mesmo Dec. permitte que fixem elles o numero de acções que dêem um voto. Com este alvitre, e com o recurso de só dar voto aos socios que tenham certo numero de acções (cit. art. 141), póde-se, de algum modo, corrigir o defeito de nossa lei (1). Acho que pódem mesmo os estatutos determinar providencias toleradas pelo art. 141 só para o computo de votos nas assembleas de eleição de administradores. O Direito frances contenta-se com a simples maioria relativa. (Vavasseur, n. 791 e Pandectes Françaises, Société, n. 11253). Vampré entende que a maioria de que fala a legislação consolidada no

(1) Contra ésta opiniāo está 'Troplong, Contract de Société, v. 2 , n. 722 , partidario do numero, mesmo em direito racional 
art. 132 do D. 434, é a absoluta. O modo por que se exprimem nossas leis dá razão a Vampré. Assim sendo, não vejo outro recurso que o segundo escrutinio, no caso de não reunir nenhum dos candidatos maioria absoluta no primeiro. Si, no segundo escrutinio, houver empate, é de nossos costumes dar preferencia ao mais velho dos votados.

8. A este proposito, surge uma questão difficil, a meu ver. Como póde a administração eleita tornar, em caso de contestação, effectivo o seu direito? Amplo debate teve a matéria numa causa da Empreza Industrial e Colonizadora do Brasil, como se vê no Direito, v. 59, pags. 324 e segs. O Juiz Montenegro entendeu que deveria agir por imperio, e não por jurisdicção. A doutrina do juiz é perigosissima. Por ella ouve-se só uma das partes. O Juiz Pitanga do Tribunal Civil sustentou que, pela contestação, tomava a causa um caracter contencioso. Entendia que a apprehensão do acervo era medida de que não cogitou nosso regulamento n. 737. Macedo Soares doutrinava que a praxe do fôro tem autorizado essas medidas violentas. Parece-me que Macedo Soares diria melhor a corruptela, o regimen das violencias. Entretanto o notavel jct. patrio Ferreira Vianna tambem applaudiu o acto do Juiz Montenegro, sem que comtudo achasse texto legal para o justificar (C. de Mendonça, Tratado, n. 1188, nota 2). No v. 61, pags. 92 e segs. do Direito, vê-se que o mesmo Juiz Montenegro entendeu, em outro caso, que a prova não era completa, mas manteve sua doutrina de poder elle ordenar a apprehensão do acervo, no caso de prova cabal de que o requerente fôra effectivamente eleito, e de estar a directoria destituida retendo indevidamente o acervo. O caso é, pareceu-me, dos mais graves. e força é reconhecer que não se acha previsto pelas nossas leis. O Juiz fica entre os dois escolhos de agir violentamente, podendo ser instrumento de um indivíduo que não representa realmente a sociedade, ou deixar que uma directoria destituida zombe da resolução da assemblea, burlando os intuitos dos verdadeiros interessados, que tomaram parte no acto de destituição da antiga directoria.

Este último inconveniente parece-me de menos vulto... Quem elege uma directoria capaz de se re- 
bellar contra as decisões da assemblea e reter os bens sociaes, acha-se nas mesmas condições de quem entrega a gerencia de uma sociedade em commandita ou com firma a uma pessoa infiel : é responsavel pelo pouco cuidado que teve em escolher a pessoa a quem entregou seus haveres: "quod quis ex culpa sua damnum sentit nou intelligitur sentire». Acho comtudo que melhor solução sería capitular-se o acto no art. $331 \quad \begin{array}{lll}\S & 2\end{array}$ do Cod. Penal, dando-se a queixa crime, e fazendo-se a apprehensão dos bens sociaes. No curso do processo criminal, dar-se-ia á directoria antiga meios de se defender, provando a illegalidade da eleição da nova. E'sta solução parece-me apenas preferivel á dada á damnata quoestio pelos illustres jcts., mas não a julgo em absoluto boa. Entendo que o nosso Congresso deveria tomar sobre o caso uma providencia, autorizando o juiz a empossar a nova directoria, mediante processo summarissimo, ou investigação rapida, ouvidas ambas as partes em termo brevissimo.

9. Comquanto nossa legislação e as da França e da Italia digam que os administradores são mandatarios da sociedade (Bing, p. 274), ha comtudo alguma differença entre suas funcções e as do mandatario. Elies operam ora como mandatarios, ora como magistrados sociaes, zelando a execução da lei e dos estatutos (Bing, pags. 330 e segs.). Além disso, é bem claro que os mandatarios tiram seus poderes do acto em que são constituidos, ao passo que os administradores têm os seus predeterminados nos estatutos, ou no contracto social e na lei (D. 434, arts. 101 e 102). O que é certo porém é que aos administradores delega a sociedade seus direitos, do mesmo modo que ao mandatario delega o mandante os seus. As regras do mandato pódem pois ser applicadas sem inconveniente aos directores de sociedades anonymas. (Pandectes Francaises, v. Administrateur de Société Anonyme, ns. 22 a 37). O que é de utilidade práctica é nos precavermos contra o tal simile entre a sociedade anonyma e o Estado, dizendo-se, por exemplo que a administração é o poder executivo, e que a assemblea retem a soberania (Pandectes, Administrateurs, n. 27). Soberania! Até tem graça...

10. Nossa lei determinou que os administradores, antes de entrarem em exercicio, prestassem caução. A 
medida é de alcance muito pequeno, podendo-se mesmo considerar como inteiramente inefficaz, e consequentemente com a desvantagem das medidas legaes inefficazes, que dão falsa segurança. A caução póde ser prestada pelo proprio director, ou por outra pessoa (D. 434, art. 105). A caução, particularidade importante, embora inexplicavel, só póde ser feita com acções da mesma companhia. Uma unica excepção abre Vivante a ésta regra, e é a de não ser possivel ao administrador adquirir acções, por não haver no mercado de titulos (n. 539). Mais razoavel parece, em vista dos termos rigores de nossa lei, que, em tal caso, não possa o administrador exercer o cargo.

Sustenta Vampré que é licito estabelecer nos estatutos que os administradores prestem em outros valores a caução (n. 636). Não posso compartir tal parecer.

Os arts. 47 do D. 8821 e $10 \S 3$ do D. 164 só dão aos estatutos faculdade para determinarem o número de acções, e isto naturalmente pelo motivo dado, no parlamento belga, pelo deputado Vander Maesen, de que "o legislador é absolutamente incompetente para determinar o quantum de garantia de que pódem ter necessidade os accionistas». (Guillery, n. 297).

Vivante apresenta vantagens e desvantagens de ser a caução feita em acções. Entre as vantagens, menciona que o administrador, desta arte, mais se interes. será pela sorte da sociedade. Está entendido que ésta vantagem existe, quando é o proprio administrador quem cauciona sua gestão, mas não no caso de ser a garantia dada por terceiro, como faculta o art. $105 \S 3$ do D. 434 . Além desta vantagem, menciona Vivante a de ser um meio de se collocarem as acções da sociedade. Entre as desvantagens porém enumera a de baixarem as acções, diminuindo a garantia, justamente no caso de má administração, caso em que vão os accionistas precisar della, desvantagem reconhecida por outros commercialistas. Vivante critica o legislador italiano por haver permittido que a caução seja prestada por terceiro. Emfim dá como unico motivo para a manutenção deste systema de garantia, o facto de não ser do gosto dos homens de negócio a immobilização de titulos, donde a difficuldade de encon- 
trar directores para uma sociedade anonyma, si fossem os administradores obrigados a caucionar sua gestão com outros titulos que não os da companhia que vão administrar (n. 539 bis, v. 2). Tal razão não parece procedente. Longamente discute a matéria Bing (La Société an. en Dr. It., pags. 302 e segs). Estas acções assim caucionadas á sociedade, o que constitue uma excepção á regra de que não póde a companhia receber em penhor as proprias acções (art. 39 do D. 434), não são sujeitas a serem penhoradas por outros debitos dos administradores, e constituem o fundo em que tem a sociedade privilegio para se indemnizar dos prejuizos que, por sua má gestão, lhe der o administrador ( $\mathrm{Vi}$ vante, v. 2, n. 539, Vavasseur n. 82, D. 434, art. 106). A caução faz-se por termo no livro do registo das acções (D. 434 , art. $105 \$ 1$ ). Si forem ao portador, serão depositadas na caixa da sociedade, ou em poder da pessoa designada pela assemblea geral (art. $105 \S 2$ ).

Si o administrador não prestar a caução dentro de 30 dias, entende-se que não acceitou a nomeação (art. 107). Si porém, em desrespeito da lei, entra em exercicio, parece que, como bcm decidiu o Juiz Montenegro, não póde estar em juizo (Direito, v. 61, pag. 93), mas, si celebra contractos, não é justo que soffram terceiros que com elle contractaram. A sociedade deve imputar a si e a seus fiscaes (D. 434 arts. 121 e 122) o não cumprimento do preceito legal.

Comquanto defeituoso, e realmente inefficaz na maioria dos casos, é o systema de nossa lei o que foi geralmente adoptado como sendo o menos imperfeitos. Para mim, seria preferivel que nenhuma caução fosse prestada: sou inimigo das medidas que dão falsa segurança. Saibam os accionistas que, si nomearem um máu director, nenhum recurso real terão contra as consequencias da má gestão, e serão mais cuidadosos na eleição dos administradores....

11. Passarei ao estudo do modo por que devem proceder os administradores no desempenho de suas funcções. Natural é dividir a matéria em duas partes, occupando-me successivamente dos direitos, ou antes dos poderes, e dos deveres delles. Começarei pelo estudo dos poderes que a lei outorga aos administrado- 
res, e, desta fórma, guardarei a ordem do decreto consolidador n. 434. Firma nossa lei que taes poderes são estabelecidos pelos estatutos, ou pelo contracto social (art. 101), só devendo-se recorrer á disposição da lei no caso de silencio do contracto, ou dos estatutos. Já Pothier doutrinára que o administrador tem todos os poderes que cabem ao procurador geral, e sua opinião continúa a ser a seguida (Pandectes Françaises, Administrateur de Soc. An., n. 127). Permanecem pois, a tal respeito, as classicas questões relativamente á extensão do mándato geral (Vavasseur, n. 821). O assumpto é porém de Direito geral, e portanto não deve ser objecto deste artigo. A doutrina de Pothier é a que se vê consagrada no art. $101 \S 1$ do D. 434 . O limite do mandato geral é, como se sabe, o de ser o acto grave ou de natureza a trazer prejuizo ao mandante (Pimenta Bueno, Apontamentos, n. 92, Gama, Procurações, n. 50, Corrêa Telles, Dig. Port. v. 3, art. 607, Coelho da Rocha, n. 794).

A procuração geral para actos extrajudiciaes comprehende os de simples administração, e não dá poderes para a alienação (Planiol, v. 2 n. 2337, Coelho da Rocha $\S 794$, Gama $\S 27$ n. 50). Si é este o limite do mandato dos administradores, no caso de silencio dos estatutos, entendendo-se que têm elles todos os poderes necessarios para a administração, sem que possam practicar actos de alienação, ou de natureza grave, tambem é fóra de dúvida que não pódem os estatutos cercear os poderes, negando-lhes os indispensaveis para cumprirem seus deveres de gestores dos negocios sociaes e de zelosos executores da lei.

São notaveis, pelo numero e pela diversidade, os casos de dúvida na tela judiciaria ao proposito da extensão dos poderes dos administradores (Pandectes Françaises, Adm. des Soc. An., ns. 284 e segs., Dalloz, Repert. Société, C. I, S. 3, art. 1 §).

12. Interessante para a responsabilidade dos administradores é a circumstancia de poderem elles determinar as funcções que compete a cada um (Vavasseur, n. 213).

As resoluções da Directoria são tomadas por maioria dos presentes, funccionando ella com a maio- 
ria dos seus membros. Esta é a doutrina corrente (Vidari, nota ao art. 141 do Cod. It., Vavasseur, Soc., n. 815 e Pandectes Françaises, vrs. Administrateur de soc. an. n. 218, v. Société n. 11352). Os estatutos porém pódem dispor diversamente sobre o modo de deliberar o conselho de administração (Vivante, v. 2, n. 553). Como proceder em caso de empate? Parece-me que deve recorrer a directoria á assemblea geral. Sobrestando-se na execução da medida projectada, em vista da regra de Papiniano "In re pari potior est causa prohibentis» (Troplong, n. 18, Soc.) Das resoluções da directoria deve-se lavrar uma acta, assignada por todos, declarando os vencidos o seu voto para o caso de responsabilidade (Pandectes, v. Administrateur, n. 121, v. Sociétés, n. 11353). Do que fica dicto, infere-se a necessidade de ter a sociedade anonyma um livro de actas, em que fique consignado tudo quanto se deu em cada reunião da directoria (Pandectes, n. 121). A acta será lavrada pelo director designado pela maioria, si não houver um director secretario, ou si não houver disposição estatutaria dispondo outra coisa. Muitas sociedades abstêm-se de longas actas, porque temem que, em pleitos judiciaes, possam, posteriormente, os adversarios se valer do que consta nellas. Dado que o Juiz mande, na pendencia da lide, exhibir esse livro facultativo, o que é pouco provavel, tal desvantagem é amplamente compensada pelas importantes vantagens de um registo completo e minucioso das deliberações em directoria. São pois dignas de louvor aquellas directorias que fazem actas minuciosas do occorrido em suas sessòes.

13. Exposto, em synthese, que os administradores têm os poderes necessarios para a consecução do fim social, excluidos os que são relativos a actos graves, ou que possam trazer prejuizo para a companhia, resta-me enumerar alguns desses poderes. Os mais importantes actos são de alienação, e estes não pódem ser praticados pelos directores, salvo no caso de fazerem objecto da sociedade (D. 434, art. $102 \S 2$ ). O mesmo se deve dizer relativamente a contrahir obrigações, ainda que sem garantia de penhor ou de hypotheca. (D. 434, art. $102 \S 2$ ). Cabendo aos directores os poderes para nomeação de agentes e de advogados, parece li- 
vre de contestação que pódem tambem nomear empregados subalternos (Pateri Giovanni, La Società anonima, n. 229 e D. 434, art. $101 \S 2$ ). A faculdade de hypothecar e de empenhar bens sociaes lhes é tirada pelo art. $102 \S$ I do D. 434. Quanto á emissão de debentures, só é ella admissivel, mediante prévia autorização da assemblea geral, nos termos do art. I $\S 5$ do D. 177-A de 15 de Setembro de 1893. Claro é que não pódem os estatutos dar aos directores taes poderes, em vista dos termos do art. I $\S 5$ do D. 177-A, que diz: «Não se fará emissão de obrigações sem prévia deliberação da assemblea geral dos accionistas...» Têm ainda os administradores, sem necessidade de expressa menção nos estatutos, poderes para receberem as importancias devidas á sociedade, dando quitação, e para pagar as dividas pela sociedade. Sem ésta faculdade não se comprehende a vida mercantil, ou o andamento dos negocios sociaes.

Os poderes especiaes devem ser expressos nos actos de investidura dos directores. Parece-me que é ésta a doutrina mais san, embora muitos (Huc., v. 12, ns. 28 e 29 e Bento Faria n. ${ }^{\text {a } 154}$ ao art. 145 do Cod. Commercial) queiram sustentar, em matéria de mandato, ser licito descobrir poderes especiaes implicitos ou subentendidos (Troplong, Du Mandat, ns. 275 e segs., Pothier, Du Mandat, ns. 159 e segs., T. de Freitas, Cons. art. 470, Clovis, Obrigações, $\S 120$ n. 1, pag. 342, P. Bueno, Apontamentos, n. 92, Gama, Proc. $\S 27$ n. 127 e S. Paulo Jud., v. 15, pg. 56).

Quanto á capacidade para estar em juizo, ou de nomear e constituir advogado, ha a observar que é manifestamente nulla a causa quando, como alias se vê no fôro, em causas patrocinadas por advogados imperitos, é citado um unico membro da directoria, sem que os estatutos lhe tenham outorgado o poder de, por si só, representar a sociedade em juizo. Neste sentido manifesta-se Vampré (n. 621 e notas 1180 e 1181).

Ainda relativamente á faculdade de estar em juizo pela sociedade, cita Didimo (n. 254) um discurso do senaclor Meira de Vasconcellos, referindo a opinião de Pirmez sobre as restricções postas a tal direito da administração: "Le droit d'administration ne permet que 
d'intenter les actions qui ont pour object des actes d'administration ou de défendre aux mêmes actions.» Dada a difficuldade de distinguir actos de administração dos que o não são, parece me dever ser repellido este limite, que viria embaraçar a directoria no desenvolvimento de sua actividade. O exemplo dado por Pirmez, e repetido por Didimo, pareceu-me infeliz Diz Pirmez que não póde a directoria «soutenir un procès où se trouve engagé un droit immobilier de la société». Não vejo como comprehender tal acto nos enumerados no art. 102 do D. 434 . Didimo não se manifesta sobre o caso, e expõe sómente a difficuldade da matéria. Vampré porém mostra compartir a opinião de Pirmez (n. 620 e nota 1177). Para finalizar: é minha opinião que as restricções do art. 102 devem ser entendidas com prudencia, de modo a limitar-se o menos possivel a acção da directoria. Proceder de outra maneira será tolher o desenvolvimento da sociedade, exercendo uma tutela excessiva sobre a companhia. Não se deve desprezar a observação de Lafayette de que a directoria tem todos os poderes necessarios para a consecução do fim da sociedade, e destes poderes não posso excluir os de hypothecar ou empenhar bens sociaes (Didimo, n. 254, pag. 349). Neste caso, em vista da letra do art. $102 \S 2$ do D. 434 , não se póde applicar o criterio de ser o acto grave ou de poder prejudicar.

A mencionar ainda ha que os actos nullos por falta de poderes da directoria pódem ser ratificados pela assemblea, e valem tambem quando a sociedade delles se aproveitou (Vivante v. 2, n. 580, Vidari, Le Società n. 511, Pandectes Françaises, Adm., ns, 191 e 636 e segs. e D. n. 434 art. 145). No nosso Direito, pódem ser ratificados não só os actos em que os directores tenham obrado excedendo o mandato ou resolvendo de modo infeliz as difficuldades que tenham surgido nos negocios sociaes (D. n. 434, art. 145), mas tambem os que importam violação da lei e dos estatutos (art. 146). Neste último caso, digno é de se referir e lembrar que a não participação de alguns accionistas á resolução, é motivo para lhes ser mantida a acção contra a sociedade (D. 8821, arts. 74 e 75). No Direito Italiano, a ratificação tem sido objecto de controversia, parecendo- 
me digno de leitura o que a este proposito escreve $\mathrm{Pa}$ teri Giovanni (La Società Anonima, n. 253). Em matériá de ratificação é bom ter presente um ponto de doutrina de grande alcance práctico. Comquanto seja certo que a sociedade não se confunde com os accionistas (Universitas distat a singulis), entretanto, em matéria de ratificação por parte de accionistas, a regra juridica soffre profundo golpe, como se vê no art. 75 do D. 8821, consolidado no art. 146 do D. 434. Faço ésta observação, porque não me esqueço da difficuldade que o princípio doutrinal originou na Belgica, como acima disse eu.

14. Deve-se reunir a directoria com frequencia, para determinar seu modo de gerir a sociedade, fixando os proprios poderes e deveres nas especies que surgem na vida social (Pandectes, v. Adm., n. 219, Vavasseur, n. 812). Convem lembrar, como sendo importantissimo, que, si é difficil fixar, em these, os poderes dos directores, mais difficil ainda o é nos diversos casos que apparecem no curso dos negocios (Pandectes, v. Adm., ns. 125 e segs. e particularmente n. 188). Com ésta consideração, passo ao estudo dos deveres da directoria.

15. Póde o director de uma sociedade anonyma exercitar o mesmo commércio que a sociedade? Responde Vivante que sim (v. 2, n. 561). Dá como motivo não ter o legislador querido privar as sociedades anonymas dos serviços de pessoas adestradas no ramo de negócio de que se occupa a sociedade que dirigem. Cita, em nota, leis de outras nações em sentido contrário, e refere que o mesmo se dá nos estatutos dos bancos de Napoles e da Sicilia (nota 223). Por muito grandes que sejam os inconvenientes de ser o director de uma sociedade negociante no mesmo ramo, entretanto nossa lei nada dispõe a este respeito, e portanto não podemos decidir o caso de modo diverso do acceito por Vivante, visto tractar-se de uma limitação de capacidade. E' aos estatutos que cumpre pôr a restricção. Na últimá parte do art. 317 do Cod. Commercial, achamos, é certo, uma restricção relativa á capacidade do socio de industria. Argumentar por analogia, em tal caso, parece-me inteiramente descabido. Demais não poz o Codigo semelhante 
restricção noutras sociedades, e a situação do socio de industria muito differe da do director de sociedade anonyma. Emfim o proprio Codigo, nas últimas palavras do artigo, considera possivel que se convencione o contrário, o que prova que não vê nossa lei na accumulação uma coisa repugnante aos interesses da sociedade. Eis porque acompanho Vivante na solução affirmativa.

16. Logo que são investidos no cargo, devem os directores tractar de receber da antiga directoria os livros e papeis que compõem o archivo social, e empos: sar-se dos bens que formam o fundo do negócio (Vidari, Le Società, n. 472). Menciona Vidari como um dos primeiros deveres dos directores dar a precisa publicidade á sua nomeação, para o que ha providencias na lei italiana (cit. n. 472). Como disse eu, ao terminar meu artigo relativo ás assembleas, nosso Tribunal decidiu 'que não têm os administradores tal dever em face de nossa lei.

Pelos arts. 113, 123, 145, 146, 147 e outros do D. 434 , vê-se que são obrigados a ter uma escripta pela qual se saiba tudo quanto diz respeito aos socios, e ás deliberações das assembleas e da directoria (Vidari, n. 473). Menciona particularmente Vidari, como mais importantes, o livro contendo a lista dos socios, o das actas das assembleas e o da directoria (cit. n. 473).

17. Outro dever importantissimo dos directores é o da publicidade de todos os actos que a lei exige sejam levados ao conhecimento dos accionistas ou de terceiros (Vidari, ns. 474, 475 e 476). Pelo nosso D. 434, são obrigados a convocações de assembleas pela imprensa (art. 134), a publicação da lista dos accionistas, da transferencia das acções, do balanço, do relatorio e do parecer da commissão fiscal, nos termos do art. 147 do D. 434. Além disso, é dever da directoria registar, na fórma da lei, todos os actos que devem ser sujeitos a essa formalidade (D. 434, arts. 91 e outros).

Pelo art. 76 do D. 8821, qualquer pessoa póde obter certidão dos actos archivados nos termos dos arts. $32 \mathrm{e}$ 33 do mesmo decreto, e da relação nominal dos accionistas. Estes actos são: os estatutos ou a escriptura, contendo o contracto social, a lista nominativa dos sub- 
scriptores, a certidão do conhecimento do depósito da decima parte do capital, a acta da constituição da sociedade $\mathrm{e}$ a folha de que constam nomes, profissões e moradas dos administradores. No decreto consolidador n. 434, ha, como reconhece Vampré, neste ponto, um erro de referencia (Vampré, n. 819).

Cumpre pois recorrer ao decreto n. 8821 , como fiz, em vista do disposto no art. 42 do D. 164 de 17 de Janeiro de 1890.

18. Um dos pontos mais delicados dentre os referentes aos deveres dos administradores é o que manda dar aviso aos outros administradores, aquelle que tiver interesse opposto ao da companhia em qualquer operação social (D. 434 art. 112). Não é precisa a fórmula legal, nem o podia ser. Fica pois, neste particular, muito ao arbitrio do juiz, como ensina Vidari (Le Società, (n. 481). Infelizmente tem-se entendido ora com muit? rigor, ora com excessiva brandura este artigo. Em geral, a questão surge quando um director compra ou vende qualquer coisa á companhia que administra. Ha um accordão do Tribunal de São Paulo, condemnando a transacção em quaesquer circumstancias (Rev. Mensal, v. 2, pag. 349).

Como medida de prudencia, a decisão é bôa, porque corta pela raiz o mal, evitande possiveis abusos. Vidari apresenta os casos de negociarem duas sociedades tendo um director commum, e o de ser o director de uma accionista da outra. No primeiro caso, entende haver conflicto de interesses, mas não no segundo n. 481). Muito longe estou de concordar com Vidari, e não sei mesmo comprehender como poude o grande commercialista dar uma tal solução á especie. Supponhamos que se tracta de uma destas sociedades em que um accionista possue a maior parte, ou a quasi totalidade das acções. Será possivel dizer que não tenha esse accionista interesse perceptivel, ficando, como diz Vidari, no maremagno dos accionistas, de modo a não haver razão para the ser applicado o rigor da lei ? De nenhum modo: elle tem maior interesse do que o director que não é accionista (D. 434, art. 99). Para mim, a unica solução acceitavel é a que elimine a possibilidade de abusos. O arbitrio do juiz é indispensavel, por 
não se ter achado uma fórmula legal feliz, mas seja este inclinado ao rigor e não á benevolencia. Tão facil é ao director impedido fazer-se substituir!...

Nos tribunaes franceses, tem-se julgado que, quando um director tem muitas acções da sociedade com que vae tractar a de que é director, ha o interesse opposto, e surge o impedimento, mas não na hypothese contrária que é a de ter poucas acções (Pandectes Françaises, ns. 232, 233 e 234 e Vavasseur, n. 825). Parece-me imprudente a distincção.

Pelos casos de que nos dão notícias as Pandectas Francesas (Administrateur, ns. 226 e segs.), bem se mostra a necessidade de reduzir ao minimo o arbitrio do juiz, e condemnar todo o acto em que o director tenha qualquer interesse por menor que seja contra a sociedade que dirige. Vivante parece mais severo com o caso (v. 2, n. 562). A simples leitura dos preceitos das leis consolidadas no art. 112 do D. 434, basta para nos dar uma idéa da severidade com que o nosso legislador quiz reprimir ésta fraude. Notem-se as cautelas da nossa lei: diz interesse, sem distinguir directo de indirecto, fala em qualquer operaçâo, abrangendo ainda as de pequeno valor pecuniario, obriga a dar $o$ aviso, quer ainda que o aviso conste da acta, unico meio de escapar o director da responsabilidade, e finalmente fulmina tres penas contra o acto evindentemente abominado, que são a nullidade do acto, a responsabilidade por perdas e damnos por parte do director e a pena criminal. Si a lei chega a considerar o acto delictuoso, ou particularmente grave, difficilmente haverá caso em que se possa dizer que não é illicito Para terminar, é bom observar que, no nosso systema juridico, diversamente do que succede em França, a prohibição é de ordem pública, não podendo a assemblea dispensar o director desse dever embora possa ratificar (D. 434, art. 146 e Pandectes Françaises, n. 223). Evidentemente a nossa lei é que está com a bôa doutrina. Desta minha consideração é corollario que a assemblea não póde ratificar o acto do director para o effeito de o livrar da pena criminal.

O crime é o previsto no art. $338 \S 5$ do Codigo Penal, parecendo que o art. 232 se occupa de empregados publicos. E' crime de acção pública. Este assum- 
pto é dos mais delicados e subtis. Relaciona-se intimamente com os institutos de nullidade e ratificação de actos juridicos e depende das doutrinas sobre dolo, fraude e culpa no civel e no crime: Mais de espaço hei de me occupar com elle, ao tractar da responsabilidade dos administradores.

19. Um dos importantes deveres dos administradores é o de não comprarem para a sociedade as proprias acções. Observa Thaller que, comquanto a prohibição não exista na letra da lei francesa, tem ella entretanto sido acceita na doutrina em França. A lei italiana é no sentido da nossa (Cod. It., art. 144). Nossa lei veda a compra e venda, mas não a amortização A matéria foi muito bem elucidada pelos commercialistas. Refere Vavasseur que muitos commercialistas entenderam que, no caso de prosperidade de uma empresa. nenhum inconveniente póde offerecer a compra que ella faça de suas proprias acções ( $\mathrm{Tr}$. des Soc., n. 383), sustentando mesmo alguns a legalidade do negócio no Direito Frances positivo. Thaller mostra que, quando as acções de uma sociedade baixam sem motivo, póde a directoria, pela compra, sustentar o preço dellas (Tr. de Dr. Commercial, n. 664), mas observa que o jogo é perigoso, citando até casos de insuccessos e fracasso. O motivo verdadeiro da prohibição legal é, a meu ver, o apresentado por Thaller. Ha, nessa compra, diminuição do capital ou da garantia que a sociedade offerece a terceiros, particularmente aos credores (Troplong, Contrat de Société, n. 444). Facil é isto de se comprehender. Si as acções não estão integralizadas, o accionista deixará de ser responsavel pelas entradas, e retirará da sociedade aquillo com que entrou. $\mathrm{Si}$ as acções se acham integralizadas, o accionista recebe a importancia que formava parte do fundo de garantia para os credores. Pateri Giovanni (n. 330) apresenta tres motivos que são: 1) diminuir ou tornar illusoria a garantia dada pelo capital da sociedade, 2) dar á sociedade uma falsa apparencia de bom estado, e 3) facilitar á directoria meios de ter maioria ficticia nas assembleas.

Nas condições porém definidas pela nossa lei e pela italiana, cessam os motivos da prohibição. Os requisitos são: $10^{\circ}$ amortizar-se a acção, de modo que não possa mais a directoria lançal-a na circulação, evitando- 
se destarte o jogo, e $2 .^{\circ}$ ser o resgate feito com os fundos disponiveis, isto é, com os lucros liquidos, ou uttili regolarmente accertati, como diz o Codigo Italiano, sendo a verificação de taes lucros effectuada "per mezzo di bilancio", dizem Vidari (nota 2 ao art. 144 do Cod. It.) e outros. Nossa lei, ainda com redundancia, ou para tornar mais claro o que sejam fundos disponiveis, accrescenta sem offensa do capital. Dahi se infere que a preoccupação do nosso legislador era não diminuir a garantia de terceiros.

Requer ainda a lei patria que a amortização seja resolvida por assemblea constituida por socios representando pelo menos dois terços do capital social. Qual o motivo dessa exigencia? Ha sempre uma desigualdade entre os socios, em caso de amortização. Póde se resolver que as acções fiquem convertidas em acções de gozo (termo que Vavasseur acha improprio querendo substituil-o pela denominação acçôes beneficiarias), ou excluir por completo o. socio da sociedade. Póde, além disso, ser resolvido que a amortização se faça por meio de sorteio. Pela nossa lei, não vejo inconveniente em que se realize amortização parcial, contrariamente ao que dispõe o Codigo Italiano (art 144). Diz Vidari que, em tal caso, dá-se uma diminuição indebita do capital. Não vejo como possa o grande commercialista chegar a ésta conclusão, attendendo eu á circumstancia de se fazer amortização pelos lucros liquidos, e não á custa do capital social.

Sobre o que sejam lucros liquidos, e que taes lucros não existem emquanto a sociedade tiver credores, manifestaram seus pareceres os luzeiros do fôro do Rio de Janeiro (Dir., v. 67, pags. 6 e segs.)

Não pódem ser lançadas de novo em circulação éstas acções, alias não teria explicação a differença dos vocabulos comprar e vender e amortização, que se nota no art. 40 do D. 434. Outra solução póde ser dada ao caso no Direito italiano (Vivante, v. 2, n. 602) Esta solução é tanto mais acceitavel, quanto é certo que o proprio Vivante, acompanhando a opinião do Congresso de Paris, celebrado em 1889, diz que tal revenda dá logar a muitos abusos (nota 271 ao n. 602).

A reclamação contra o acto praticado só póde ser apresentada pelos credores da sociedade e por ésta, e 
não pelos vendedores (Vivante. v. 2, n. 599). Dà prohibição de comprar as sociedades as proprias acções dimana a de não as receber em caução (Pateri Giovanni, La Società, n. 230), que é um começo de alienação, havendo pois coherencia no que dispõe a tal proposito o nosso D. 434 no art. 39. Nenhumd incoherencia ha entre o disposto neste art. 39 e o que preceitúa o art. 105, relativamente á caução da directoria, a fazer-se em acções da propria companhia, porque, como acima ficou dicto, a acquisição de acções pela propria sociedade só tem inconvenientes em razão dos abusos a que póde dar logar, quando deixada a criterio da administração que póde usar desta faculdade em proveito seu, e em prejuizo de terceiros e da propria companhia.

20. Na lei relativa ás sociedades anonymas, não encontramos disposição que se occupe com o modo por que devem ser applicados os fundos sociaes. Nos estatutos, por vezes, ha preceitos formaes, e até fixação do juro minimo a cobrar. Outras vezes, isto resulta da natureza da sociedade. Exemplo frisante desta última hypothese é o de uma sociedade de crédito hypothecario. Relativamente ás sociedades de seguros, anonymas ou mútuas, tem o Governo prescripto em leis algumas regras (D. 5072, art. 2, ns. 1 e 2), sujeitando-se a sociedade a ver cassada sua carta patente de autorização, no caso de inobservancia desta disposição da lei (cit. D. 5072, art. 63 n. 1). Nos demais casos, incorrem os administradores em culpa por falta do cumprímento dos estatutos (D. 434, arts. 109 e 110). Conhecido é que, não raro, entendem os administradores de sociedades anonymas que só não pódem usar em proveito proprio dos bens que lhe são confiados no caso de lhes ser isto vedado pelos estatutos. Nada mais absurdo do que tal intelligencia dos deveres de director. Si o director desencaminha fundos que the são confiados em proveito seu, ou mesmo de amigos, incorre em responsabilidade civil e mesmo penal, como mostrarei quando tractar da responsabilidade dos administradores de sociedades anonymas (Cod. Penal, art. 338 §5).

21. Durante a vida da sociedade portanto, são os deveres da administração: tomar posse do cargo, ter 
os livros necessarios, manter em boa ordem o archivo, tornar effectiva a publicidade de certos actos que a lei julgou de interesse de terceiros, nomear agentes e outros empregados para regular andamento dos negocios da companhia, observar as prescripções legaes e estatutarias relativas ao emprego do capital social, não se esquecendo de que não póde comprar nem vender acções da sociedade, nem as receber em caução e de que deve dar aos fundos sociaes a applicação consentanea com o fim que se propuzeram os accionistas ao constituir a sociedade, prestar caução na fórma da leí e ser zelosa em reunir-se e deliberar sobre os interesses sociaes.

Verei agora o que the cumpre fazer, quando a sociedade vae mal, e tende á ruina. Para as sociedades anonymas, ha hoje os dois alvitres: a liquidação amigavel e a fallencia. Nos casos de cessação de pagamento das dividas, insolvencia, perda de tres quartos ou mais do capital social, entrava a sociedade em $l i$ quidação forçada, e aos directores cumpria requerer tal liquidação (D. 434, arts. $167 \S \S 1,2$ e 3 e 169, parte final).

Faz sentir Vampré que o capital de que se tracta é o nominal e nâo o realizado, pois, emquanto não se realiza o capital, pódem as perdas ser cobertas pelas chamadas (n. 858). Funda-se em boas autoridades (nota 1573).

Hoje, pelo D. 2024, a cessação de pagamentos e a perda de tres quartos ou mais do capital são motivos para se julgar fallida a sociedade anonyma (D. 2024, art. 3), devendo os administradores requerer a fallencia da companhiá dentro do prazo de dez dias (D. 2024, art. $8 \S 2)$. Mas, no caso de insolvencia, como devem proceder os administradores? Segundo C. de Mendonça, o insolvente não tem direito de requerer a propria fallencia. O illustre Professor Dr. Steidel, ao contrário, sustenta que ahi se dá uma cessação virtual de pagamentos, e, acompanhando Vidari, Bolafio, Luciani e outros, entende que, em tal hypothese, é facultado ao negociante requerer sua propria fallencia (Licção 25 do curso de 1915). A doutrina do Dr. Steidel pareceme preferivel. 
Continúa porém a difficuldade, ainda que se acceite a opinião do Dr. Steidel, acerca do seguinte ponto: poderá porém a sociedade optar pela liquidação forçada? Julgo que a negativa se impõe. Si a cessação virtual deve se equiparar á real, claro se mostra que deve produzir os mesmos effeitos. Razoavel é pois que, a contar do dia em que se ache a sociedade em estado de insolvencia, dentro de dez dias, deva ter sua fallencia requerida por seus directores. Com o cumprimento deste importante dever (Vidari, Le Società, n. 493), não terminam as funções dos directores. Fallida a sociedade, ainda lhes cumpre propor a concordata, podendo para tal effeito, convocar a assemblea geral, ou ao menos uma reunião de accionistas (D. 2024, art. $103 \S 2$ ).

No caso de se reduzir o numero de socios a menos de sete, e de perdurar ésta reducção por seis mezes, têm os administradores obrigação de requerer a declaração judicial de que está a sociedade dissolvida, sob pena de responderem pelos actos que se praticarem em nome da sociedade (D. 164 de 17 de Janeiro (de 1890, art. 17), sendo de notar que tal pedido póde partir da commissão fiscal e de qualquer accionista, ou ainda poder ser a dissolução decretada ex-officio pelo juiz (Vampré, n. 859). Terminam pois as sociedades anonymas antes de seu prazo fixado em lei ou nos estatutos, pela fallencia ou pela liquidação amigavel.

Expostos os deveres mais importantes dos directores, só resta lembrar que, no desempenho do mandato, devem ter sempre presente quão delicada é a posição de quem administra bens alheios.

22. Occupar-me-ei agora dos casos em que devem os directores deixar a administração da sociedade.

O administrador póde deixar a direcção da sociedade voluntaria ou involuntariamente. A assemblea tem a faculdade de o exonerar sem dar motivos (D. 434, art. $97 \S 1$ ). Julga Vivante necessario advertir que não póde a sociedade destituir do cargo, o director nomeado pelo Governo, por força dos estatutos ou da lei (Vivante, v 2, n. 536). Nada mais resta a dizer sinão que, quanto a este caso de exoneração, e a tudo o 
mais que diz respeito á substituição dos administradores, a applicação das regras do mandato tem inteiro cabimento (Vivante, v 2, n. 536, Vampré, ns. 601 e segs.), donde algumas questões de alcance práctico. Uma é si pódem os estatutos estabelecer expressamente que não seja revogavel por certo tempo o mandato. Esta questão dividiu a jurisprudencia francesa, como se vê em Vavasseur (n. 795). Parece-me que o preceito da lei permittindo a revogação do mandato dos administradores em qualquer tempo, é de ordem pública, como ensina Vavasseur, e portanto não pódem os estatutos derogal-o. Uma outra consideração leva-me a não applicar por analogia, neste ponto, os principios do mandato em causa propria ás sociedades anonymas, e vem a ser que tal especie de mandato tem sido sempre fonte de toda sorte de abusos e fraudes. A outra questão é si, com causa justificativa, pódem alguns accionistas pedir judicialmente a destituição dos administradores (Vavasseur). Sería isto muito desejavel, mas não vejo acção efficaz para tal se impetrar. Demais, ha o $\S 2$ do art. 97, que dá este poder sómente á assemblea geral. Resta aos accionistas acção de perdas e damnos contra os administradores, e, em dadas hypotheses, o direito de pedir a dissolução da sociedade.

Observa, com toda a razão, Vampré, seguindo os mestres de Direito Mercantil, que, na práctica, encontra difficuldades o exercicio desse direito, por serem os directores que convocam a assemblea dandolhe a ordem do dia, assemblea que é o unico poder competente para os exonerar. Dois casos porem ha em que se poderá conseguir a exoneração, sendo o primeiro o de terem os proprios accionistas feito a convocação, nos termos dos arts. 137 e 138 do D. 434, e o segundo o de surgir a questão durante a sessão de assemblea, pois, como é sabido, a determinação prévia da ordem do dia ou das matérias a debater na assemblea é uma medida de protecção aos accionistas, não sendo nullo o que resolverem elles sobre matéria que não tivesse figurado nos annuncios de convocação (Vampré, n. 604).

Além do que fica dicto, quanto á fórma de revogação dos poderes dos administradores e quanto aos 
casos em que ella se póde dar, os principios do mandato têm completa applicação (Vampré ns. 606 e 607).

23. Nada preceitua nossa lei consolidada no D. 434 sobre os casos em que se torna o administrador incapaz de continuar no exercicio do cargo. Occupa-se da hypothese o Codigo Italiano no art. 151. Parece-me que devem ser applicados á difficuldade os principios geraes estabelecidos no Direito Civil e no Commercial acerca da capacidade.

Emfim póde se exonerar o proprio director livremente, por sua resolução.

Que providencias dar nestes casos em que desapparecem os administradores sem haver immediata eleição de substitutos pela assemblea?

24. Póde o administrador exonerar-se, mas não tem direito de deixar o exercicio antes que dê á assemblea conhecimento de sua resolução: é a regra que rege o mandato (Corrêa Telles, Dig. Port., v. 3, arts. 641 e 642). Claro é pois que deve pedir aos companheiros que convoquem a assemblea geral. Si morre um dos administradores, ou fica, por qualquer circumstancia inhabil para o cargo, aos demais corre o dever de fazer immediata convocação da assemblea geral, para que lhe dê substituto, e nomear, de accordo com os fiscaes, um provisorio (D. 434, art. 103). A convocação da assemblea não se dará quando os estatutos contiverem disposição acerca do modo de substituição do administrador que faltar (D. 434, art. 103). O substituto servirá pelo tempo que cabia ao substituido para terminar seu mandato (Vidari, Le Società, n. 353 D. 434 art. 104). E' matéria de que me occupei no princípio deste artigo (n. 2).

JoĀo ARRUda. 